\title{
The new format Primary Care Respiratory Journal
}

Well, here we are as promised-the first issue of the Journal to be published by Elsevier/Saunders, one of the biggest scientific publishing houses in the world. After many months of deliberation, and discussion of the whys and wherefores, it is very exciting to see the new look Journal in all its glory.

As you can see, we have a much more substantial journal on offer, with an increased number of original papers from the cutting edge of primary care respiratory medicine, as well as our usual high quality reviews and editorials. Our News section will continue unabated, and we look forward to hearing from you with any snippets of information that will interest the readership. Are you planning an interesting PCT initiative to help develop respiratory care in your area of the UK? How are you grappling with the quality indicators for asthma and COPD in your practice as we implement the new GP contract-particularly if spirometry provision is scarce in your area? How about national or local developments in Europe and the rest of the world? How are your national primary care respiratory groups flourishing?

These are the questions we want answering. As the PCRJ develops, we hope that it will continue to provide an invaluable forum for announcements and discussion of news and information from all over the world relating to respiratory medicine in Primary Care. In addition, we are particularly keen to develop further our Letters section; let us know your opinions on the papers and articles in the Journal this issue. Letters to the Editor should be no more than 400 words in length, containing a maximum of five references plus one illustration or table and sent to publishing@gpiag.org.

Let us know what you think of the new-look PCRJ, and tell your colleagues to read it too!

Dr Paul Stephenson Assistant Editor

\section{Developments at the ERS}

The annual European Respiratory Society meeting is very much a definite fixture for many of us with an interest in managing respiratory disease in primary care. The recent meeting in Vienna last September was no exception, with some superb presentations and discussion as usual.

In particular, the Primary Care Group of the ERS is developing fast. This group consists of all those ERS members who work mainly in primary care, and the size of the group is increasing all the time. Professor Onno van Schayck was the first chairman of the Group, and at the recent annual meeting which took place during the Vienna conference he handed over the chairmanship reins to Dr Mark Levy, who had previously been Secretary of the group. Mark will be ably assisted by Mrs Monica Fletcher, the new secretary. We are enormously grateful to Onno for all of his hard work over the last few years, and we know that he will be a very supportive influence in the future.

A major issue for the group over the next year or two will be to establish its role in relation to the other interest groups made up of special interest chest physicians in the main, but with a scattering of cardiothoracic surgeons, occupational physicians, allied professions, radiologists and anaesthetists, to name but a few. All groups are components of approximately ten larger groupings, the Scientific Assemblies, representatives of which meet regularly in order to plan the programme for the ERS meetings.

The Primary Care Group is at present a member of the 'Clinical' Scientific Assembly, which happens to be the biggest Assembly, and because of this a small group such as ours can sometimes find it difficult to make its voice heard. However, Monica, Onno and Mark can be very proud of themselves after Vienna-we had several Major Symposia which 
were wholly or partly organised by the Primary Care Group, as well as numerous smaller oral presentation and poster sessions. There is now no doubt that the Primary Care Group is a very important and influential grouping within the structure of the ERS, and this can only be of benefit to the organisation as a whole.

This year's ERS meeting will be in Glasgow, preceded by the Annual Meeting of the GPIAG. If you're thinking about going up to Glasgow, then do so! While you're there, register yourself as a member of the ERS, and as a member of the Primary Care Group within the ERS. That way we can be even more influential. We have some important decisions to make over the next year or two regarding the Group's membership of a Scientific Assembly-should we remain as one of a number of groups in the large Clinical Assembly, or should we look to join a different smaller Assembly which may provide us with more opportunity to develop the primary care agenda? It's important that we receive a wide spectrum of primary care opinion on this, and so we would be delighted to receive letters on this issue which will be published in the Journal. Email us at publishing@gpiag.org.

Dr Paul Stephenson Assistant Editor

\section{Meetings \\ GPIAG announce two further meetings to help your practice achieve the respiratory targets. in the New GMS Contract \\ 117 points are linked to the care of asthma and COPD}

Following the very successful GP Contract meeting in Crewe we are delighted to announce that we will be holding a further two meetings focusing on achieving the respiratory aspects of the new GMS Contract in March 2004.

As practicing clinicians we understand the problems of trying to achieve targets in the busy world of general practice.

We would like to invite you to an interactive meeting at which we will discuss clinical aspects of care, practical procedures and organisational issues that will help your practice achieve targets. The speakers at the meeting will be national opinion leaders in respiratory care, but with their feet firmly on the ground of general practice.

The meeting is designed for the following.
General practitioners

Practice managers
Respiratory nurses

PCT leads with an interest in improving care
The programme will include a series of interactive practical workshops which focus on delivery of quality care within the structure of the new guidelines and encompasses diagnosis of asthma and COPD and their management and meeting the new respiratory targets.

Venues: The North East of the UK (Durham area) and the South West of the UK (Exeter/Bristol area).

For further information on how to register and details of registration fees contact the gpiag for a registration form on +44-121-454-8219 or email info@gpiag.org.

\section{General Practice Airways Group advance notification}

Practitioners with a special interest in respiratory disease GPs with a special interest in respiratory disease

Training workshop-June 2004, London

Aim of workshop: a 1-day workshop to develop skills relevant to a practitioner with a special interest in primary and intermediate care respiratory medicine.

Target audience: nurses and general practitioners who are, or hope to become, practitioners with a special interest in primary or intermediate care respiratory medicine.

Programme includes strategic and management skills to assist you at policy level within your local area.

For more information: Contact the GPIAG, email info@gpiag.org or telephone +44-121-454-8219.

\section{Announcing a new short course from the National Respiratory Training Centre}

GMS contract: implications for respiratory disease

Book individual places in Warwick

OR

\section{Book a course to run in your local PCT area}

The National Respiratory Training Centre (NRTC) has designed and produced this new short course to enable health professionals and primary care organisations to fulfil their contractual requirements but more importantly to improve the care of patients with respiratory disease. Learning outcomes will ensure that you are able to provide relevant and appropriate examples of evidence which satisfy the requirement of the GMS Contract and $\mathrm{CHI}$ reviews. 
You will develop the competence to identify a clear plan of action and the confidence to help deliver it.

This interactive 1 day short course will focus on a number of key issues that underpin the delivery of the contract for respiratory disease and will offer practical information as well as facilitate discussion in order to share good practice. Book your place for $\mathrm{£} 85$

Contact: Ellie Sargent, $+44-1926-838973$ or

email e.sargent@nrtc.uk

Book your 20 place course to your area for your team or PCT for $£ 1400$

Contact: Candy Perry, $+44-1926-836995$ or email

c.perry@nrtc.org.uk

\section{Diary dates}

See also http://www.gpiag.org/news

Royal College of Physicians/British Thoracic Society

Acute care for patients with chronic obstructive pulmonary disease

4 March 2004
Royal College of Physicians, London

Online registration

http://www.rcplondon.ac.uk/calendar/2004/ conf_2004_acpcopd.htm

Primary Care Clinical Update Meeting 2004

2-3 September 2004

Birmingham, UK

Online registration

http://www.fbpcs.org.uk

GPIAG Annual Meeting

3-4 September 2004

Glasgow UK

Further information

info@gpiag.org

European Respiratory Society

Annual Congress

4-8 September 2004

Glasgow, UK

Online registration

http://www.ersnet.org

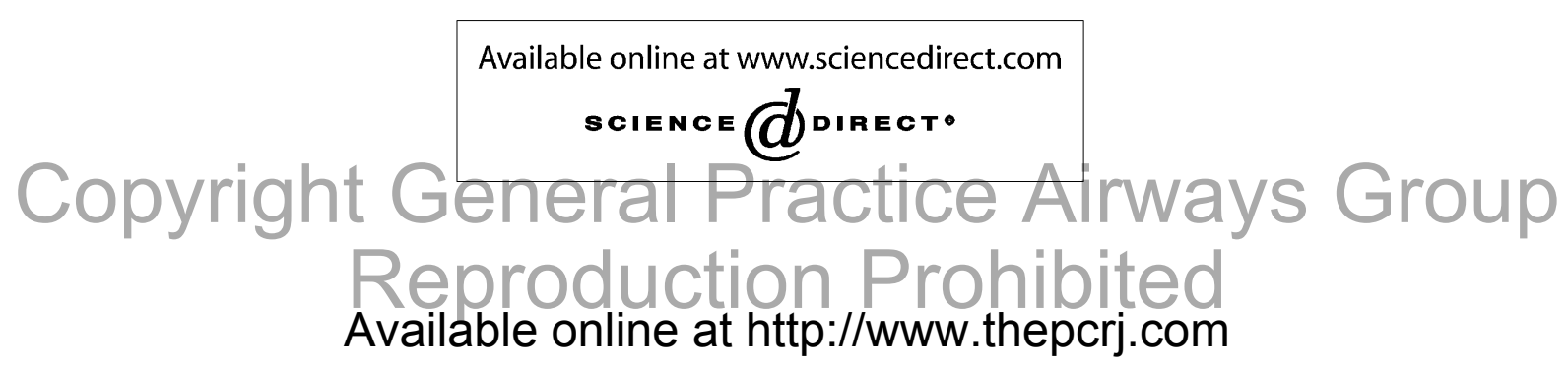

